Supporting Information

\title{
Optically Active Physical Gels with Chiral Memory Ability: Directly Prepared by Helix-Sense-Selective Polymerization
}

\author{
Huajun Huang, ${ }^{a, b}$ Jianping Deng, ${ }^{a, b} *$ Yan Shi ${ }^{a, b}$ \\ ${ }^{a}$ State Key Laboratory of Chemical Resource Engineering, Beijing University of \\ Chemical Technology, Beijing 100029, China \\ ${ }^{\mathrm{b}}$ College of Materials Science and Engineering, Beijing University of Chemical \\ Technology, Beijing 100029, China
}

Table S1. Data for the gels and corresponding polymers. ${ }^{\text {a }}$

\begin{tabular}{cccc}
\hline $\begin{array}{c}\text { Concentration of } \\
\text { monomer } \\
\text { (mol/L) }\end{array}$ & $\mathrm{Mn}^{\mathrm{b}}$ & $\mathrm{Mw} / \mathrm{Mn}^{\mathrm{b}}$ & $\begin{array}{c}\text { Yield }^{\mathrm{c}} \\
(\mathrm{wt} \%)\end{array}$ \\
\hline 0.05 (without \\
chiral additive) & 93000 & 1.57 & 89 \\
0.1 (R-PEA) & 85200 & 1.56 & 88 \\
0.05 (R-PEA) & 83700 & 1.59 & 90 \\
0.025 (R-PEA) & 86100 & 1.54 & 90 \\
0.017 (R-PEA) & 79500 & 1.69 & 81 \\
0.05 (S-PEA) & 79400 & 1.58 & 88 \\
\hline
\end{tabular}

${ }^{\text {a }}$ Preparation conditions: the ratio of $[\mathrm{Rh}] /[\mathrm{M}]$ was $1 / 100(\mathrm{~mol} / \mathrm{mol})$; the ratio of chiral $\mathrm{PEAs} / \mathrm{CHCl}_{3}$ was $1 / 100(\mathrm{v} / \mathrm{v})$.

${ }^{\mathrm{b}}$ Determined by GPC with polystyrenes as standard, DMAC as eluent.

${ }^{\mathrm{c}}$ Determined by weighing the solid product after freeze-dried. 
Table S2. Comparison of the mass loss rate of the gels ${ }^{\mathrm{a}}$ after heated at $200{ }^{\circ} \mathrm{C}$ for 30 min in vacuum.

\begin{tabular}{cccccc}
\hline $\begin{array}{c}\text { Dried } \\
\text { gels }\end{array}$ & $\begin{array}{c}\text { Synthesized } \\
\text { without chiral }^{\text {additive }}\end{array}$ & $\begin{array}{c}\text { Synthesized } \\
\text { with R-PEA }^{\mathrm{b}}\end{array}$ & $\begin{array}{c}\text { Synthesized } \\
\text { with S-PEA }^{\mathrm{b}}\end{array}$ & $\begin{array}{c}\text { Synthesized } \\
\text { with R-PEA }^{\mathrm{c}}\end{array}$ & $\begin{array}{c}\text { Synthesized } \\
\text { with S-PEA }^{\mathrm{c}}\end{array}$ \\
\hline $\begin{array}{c}\text { Weight } \\
\text { loss } \\
(\%)\end{array}$ & 20.3 & 19.3 & 20.5 & 42.2 & 46.7 \\
\hline
\end{tabular}

${ }^{\mathrm{a}}$ Preparation conditions: monomer concentration $[\mathrm{M}]=0.05 \mathrm{~mol} / \mathrm{L} ;[\mathrm{Rh}] /[\mathrm{M}]=1 / 100$ $(\mathrm{mol} / \mathrm{mol}) ;$ chiral PEAs $/ \mathrm{CHCl}_{3}=1 / 100(\mathrm{v} / \mathrm{v})$.

${ }^{\mathrm{b}}$ Dried at $50{ }^{\circ} \mathrm{C}$ after washing for 5 days in $\mathrm{CHCl}_{3}$.

${ }^{\mathrm{c}}$ Directly dried at $50{ }^{\circ} \mathrm{C}$ without washing.

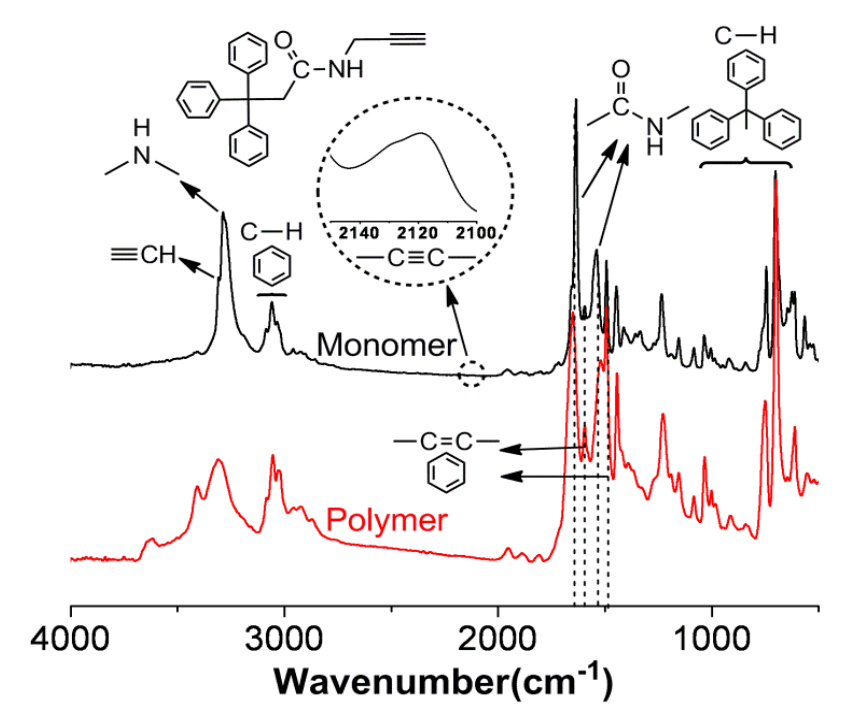

Figure S1. Typical FT-IR spectra of the monomer and corresponding polymer (originate from the achiral gel). 

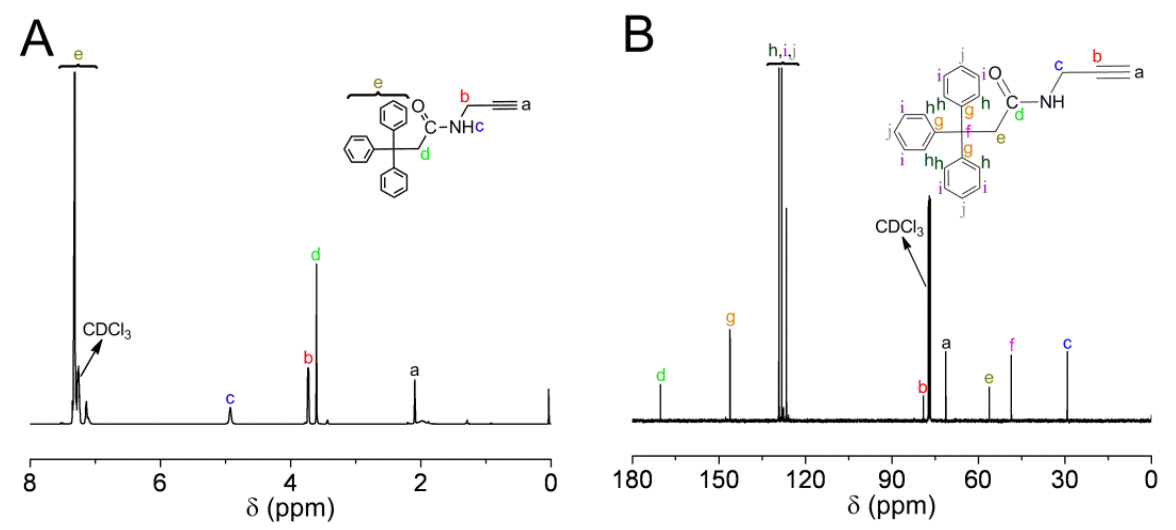

Figure S2. NMR spectra of the monomer. A, ${ }^{1} \mathrm{H}$ NMR; B, ${ }^{13} \mathrm{C}$ NMR; measured in $\mathrm{CDCl}_{3}$ at room temperature.

${ }^{1} \mathrm{H}$ NMR (400 MHz, $\mathrm{CDCl}_{3}$ ): $\delta$ 7.38-7.02 (m, 15H, Ar-H), $4.93(\mathrm{~s}, 1 \mathrm{H}, \mathrm{N}-\mathrm{H}), 3.72$

(dd, 2H, $\left.\mathrm{CH}_{2} \mathrm{~N}\right), 3.60$ (s, 2H, $\left.\mathrm{CH}_{2} \mathrm{CO}\right), 2.09$ (s, 1H, $\left.\mathrm{HC} \equiv \mathrm{C}\right)$.

${ }^{13} \mathrm{C}$ NMR (100 MHz, $\left.\mathrm{CDCl}_{3}\right): \delta 170.2,146.1,129.2,128.3,126.6,78.9,71.2,56.0$, 48.6, 29.2 .

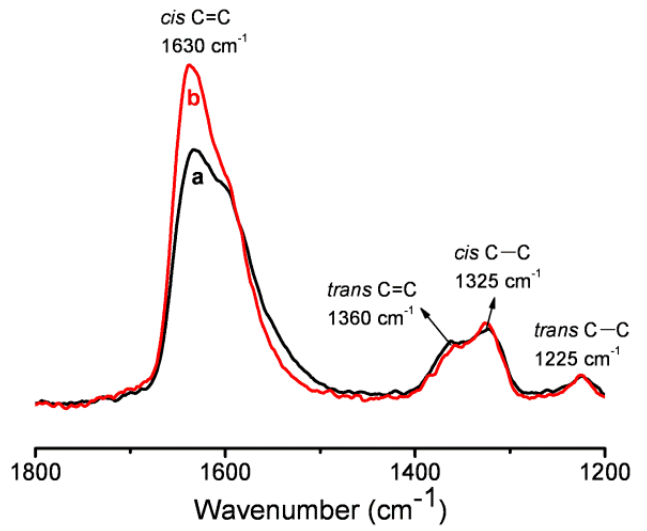

Figure S3. Typical Raman spectra of the gels (freeze-dried for measurement) synthesized with (b) or without (a) chiral additive (R-PEA), and the monomer concentration for the gel preparations is $0.05 \mathrm{~mol} / \mathrm{L}$.

The calculated cis contents of (a) and (b) are $90.6 \%$ and $93 \%$, respectively. 

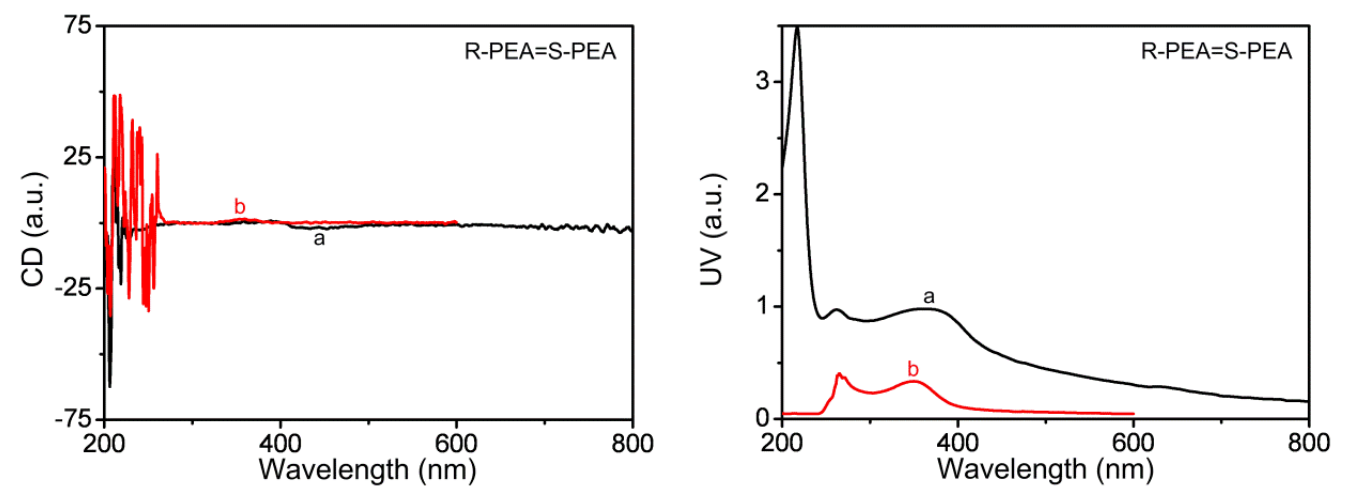

Figure S4. CD and UV-vis absorption spectra of the gel synthesized with both R- and S-PEA in identical amount. a, the resulting gel was directly pressed between two pieces of quartz glass for measurement; $b$, the polymer solution obtained by dissolving the gel in DMAC $\left(10^{-4} \mathrm{~mol} / \mathrm{L}\right)$.
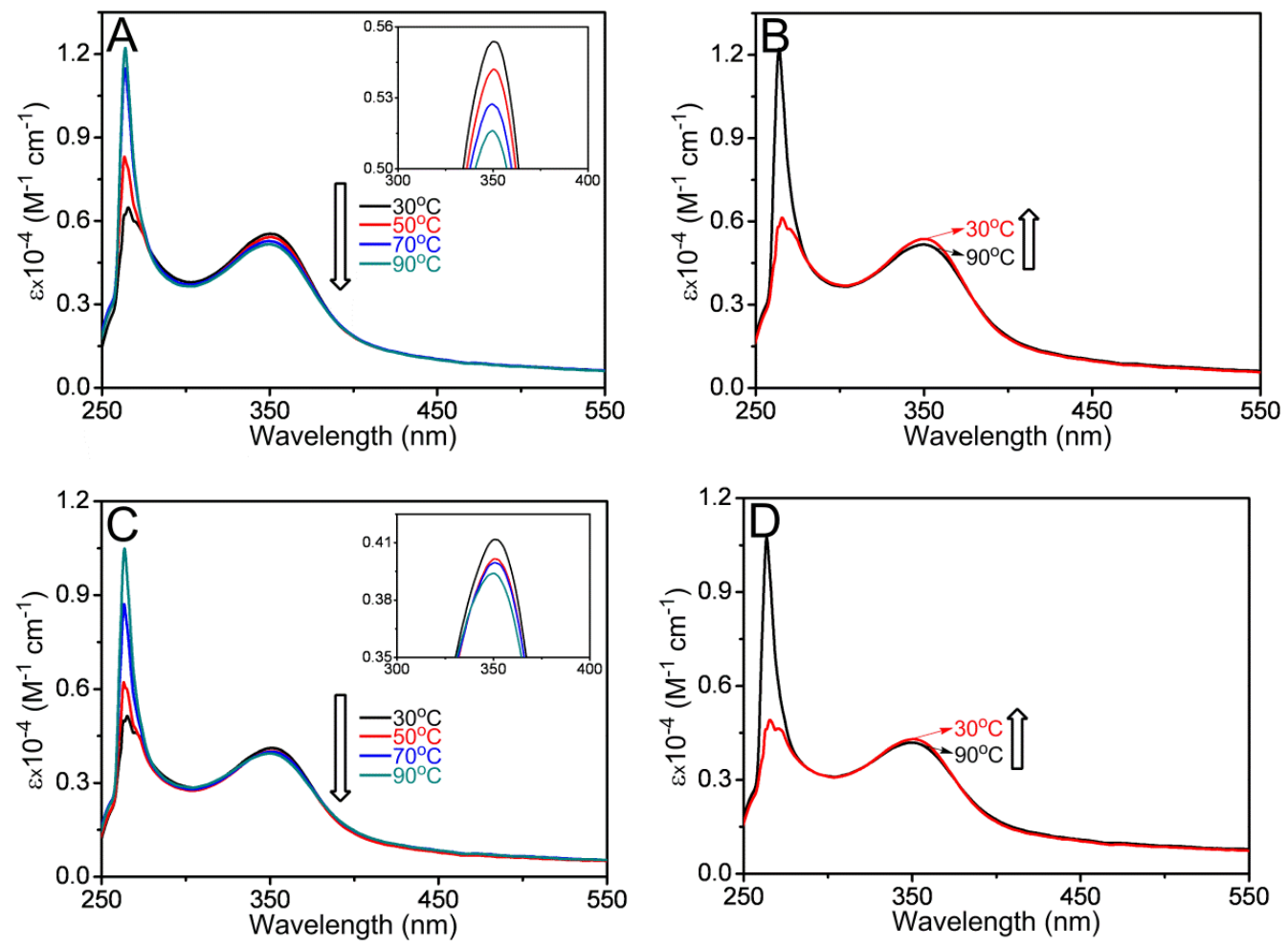

Figure S5. UV-vis absorption spectra of optically active physical gels synthesized in $\mathrm{CHCl}_{3}([\mathrm{M}]=0.05 \mathrm{~mol} / \mathrm{L})$ with R- $(\mathrm{A}, \mathrm{B})$ or S-PEA $(\mathrm{C}, \mathrm{D})$ and dissolved in DMAC with increasing $(\mathrm{A}, \mathrm{C})$ and decreasing $(\mathrm{B}, \mathrm{D})$ temperature. Concentration of the solutions, $10^{-4} \mathrm{~mol} / \mathrm{L}$ by monomer units. 

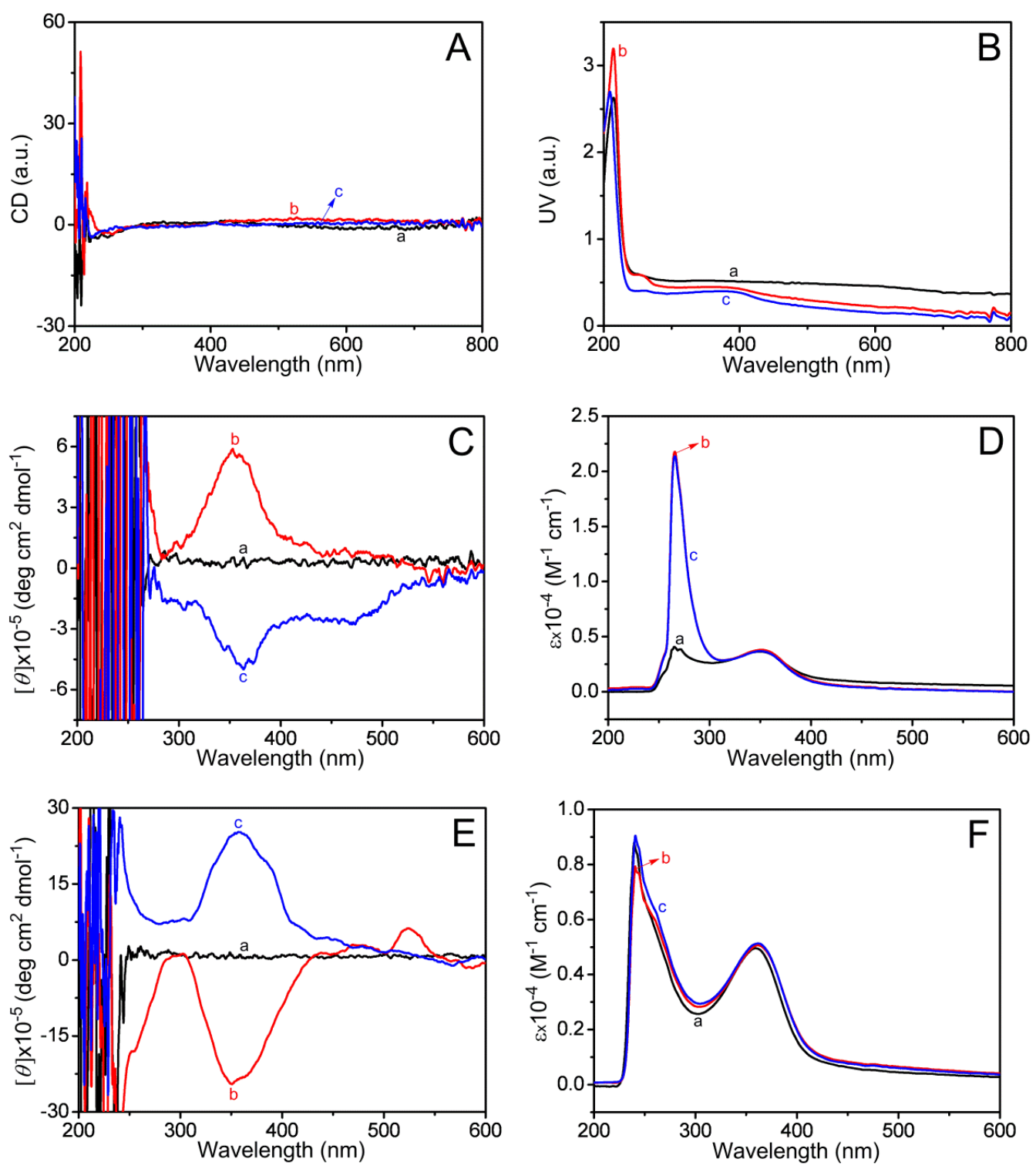

Figure S6. CD(A, C, E) and UV-vis absorption (B, D, F) spectra of polymer gels (a, original gels) which had been immersed in a $\mathrm{CHCl}_{3}$ solution of R-PEA (b) or S-PEA (c) for over $12 \mathrm{~h}$. For A and B, the gels were directly pressed between two pieces of quartz glass for measurement; For $\mathrm{C}$ and $\mathrm{D}$, the polymer $\left(10^{-4} \mathrm{~mol} / \mathrm{L}\right.$ by monomer units) was dissolved in DMAC; For $\mathrm{E}$ and $\mathrm{F}$, the polymer $\left(10^{-4} \mathrm{~mol} / \mathrm{L}\right.$ by monomer units) was dispersed in $\mathrm{CHCl}_{3}$ by ultrasonic. The ratio of chiral $\mathrm{PEAs}$ to $\mathrm{CHCl}_{3}$ in the soak solution was $1 / 100(\mathrm{v} / \mathrm{v})$. 


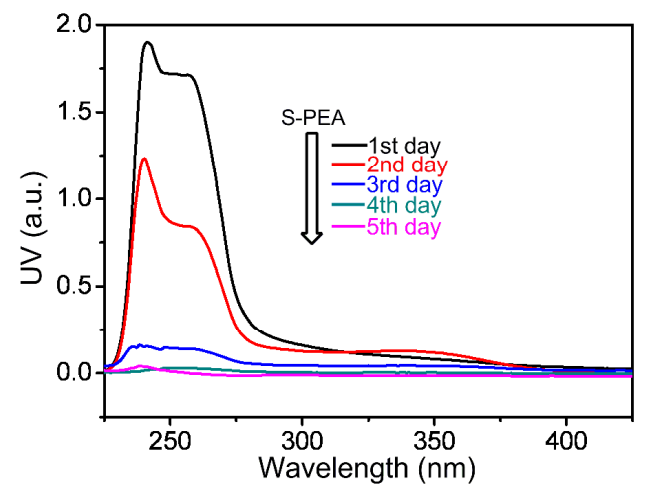

Figure S7. UV-vis absorption spectra of the eluates derived from immersing the optically active physical gel in $\mathrm{CHCl}_{3}$. S-PEA was used as chiral additive for preparing the gel.
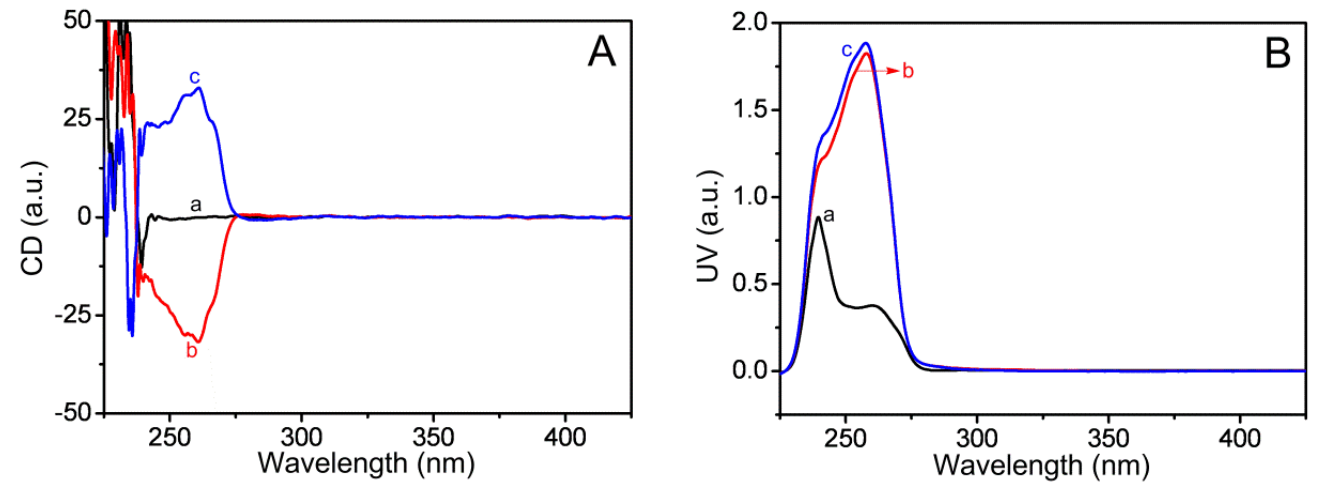

Figure S8. CD (A) and UV-vis absorption (B) spectra of the monomer (a), R-PEA (b) and S-PEA (c) dissolved in $\mathrm{CHCl}_{3}$. 


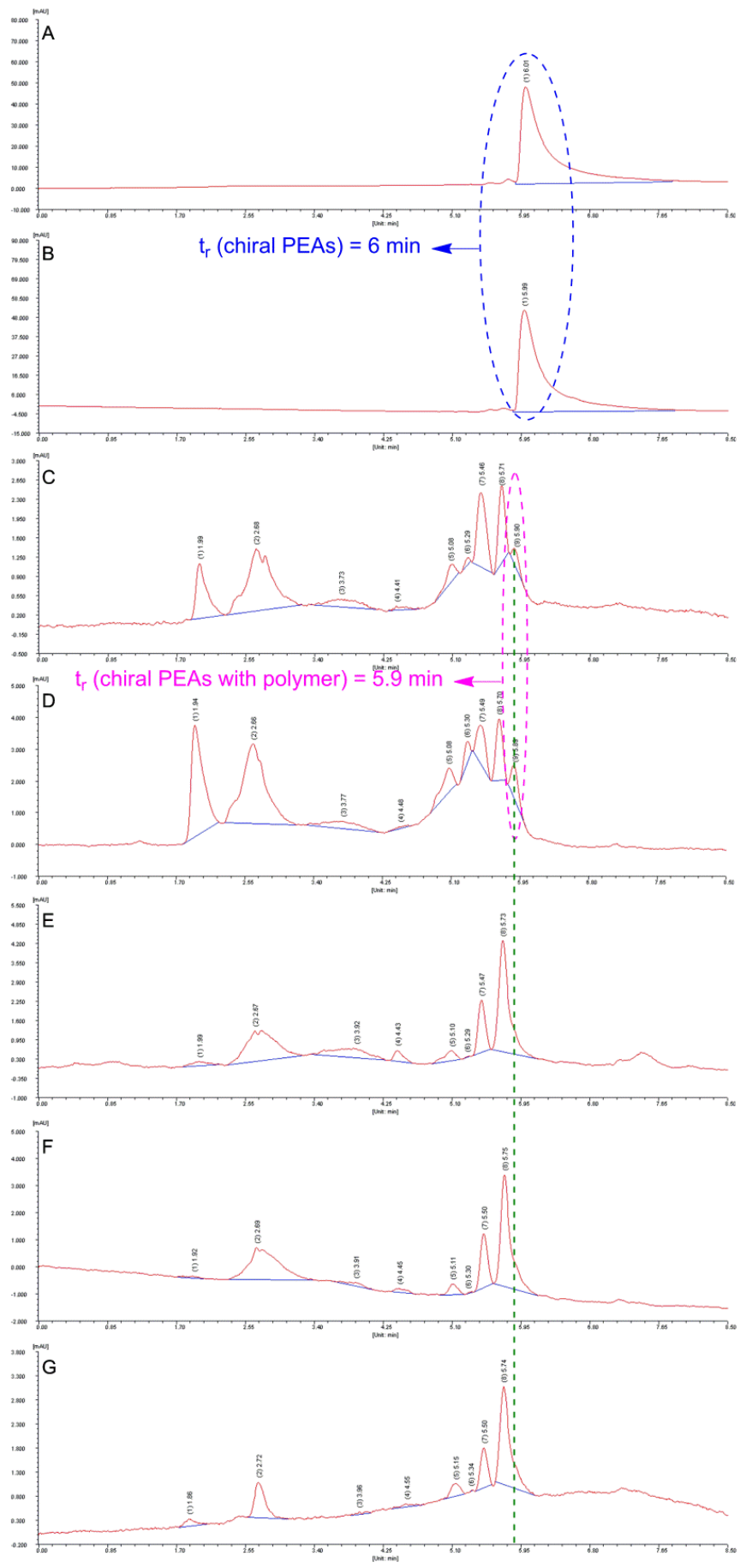

Figure S9. HPLC spectra of R-PEA (A), S-PEA (B), OAPG without washing off the chiral additive R-PEA (C), OAPG without washing off the chiral additive S-PEA (D), achiral gel after washing for 5 days in $\mathrm{CHCl}_{3}(\mathrm{E})$, OAPG after washing off the chiral additive R-PEA for 5 days in $\mathrm{CHCl}_{3}(\mathrm{~F})$, and OAPG after washing off the chiral additive S-PEA for 5 days in $\mathrm{CHCl}_{3}(\mathrm{G})$.

C18 column, $25 \times 0.46 \mathrm{~cm}$ (i.d.); eluent, DMAC; elution flow rate, $0.5 \mathrm{~mL} / \mathrm{min}$; temperature, $25{ }^{\circ} \mathrm{C}$; UV, $254 \mathrm{~nm}$. Before measurement, all the gels were completely dried up at $50{ }^{\circ} \mathrm{C}$ in vacuum till constant weight. 

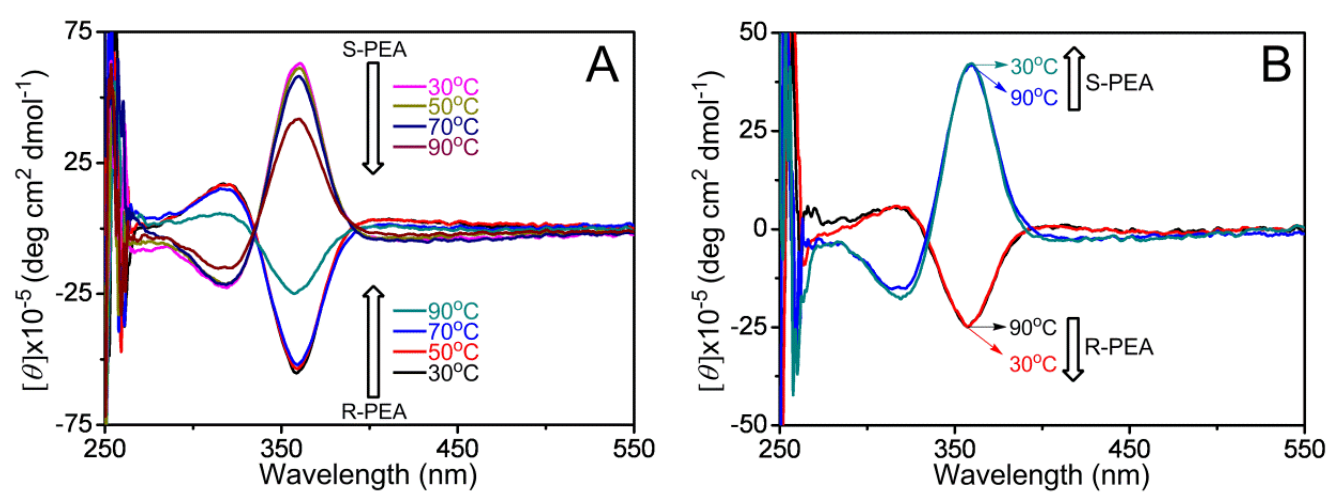

Figure S10. CD spectra of the purified OAPGs dissolved in DMAC with increasing (A) and decreasing (B) temperature. Concentration of the solutions, $10^{-4} \mathrm{~mol} / \mathrm{L}$ by monomer units.
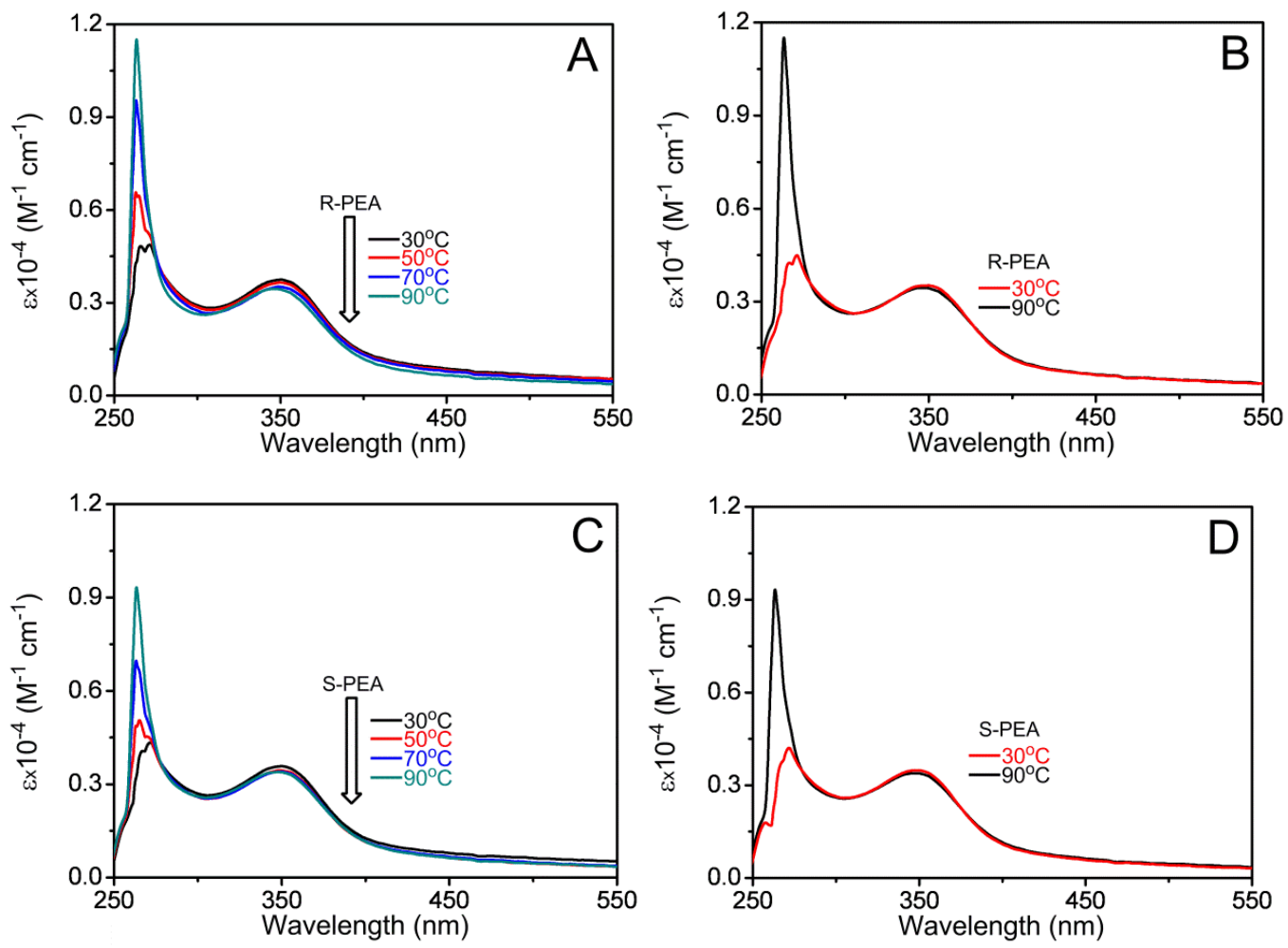

Figure S11. UV-vis spectra of the purified OAPGs dissolved in DMAC with increasing $(\mathrm{A}, \mathrm{C})$ and decreasing $(\mathrm{B}, \mathrm{D})$ temperature. Concentration of the solutions, $10^{-4} \mathrm{~mol} / \mathrm{L}$ by monomer units. 